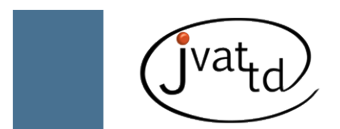

The Journal of Venomous Animals and Toxins including Tropical Diseases

ISSN 1678-9199 | 2011 | volume 17 | issue 3 | pages 287-292

\title{
Postprandial thermogenesis in Bothrops moojeni (Serpentes: Viperidae)
}

\author{
Stuginski DR (1), Fernandes W (1), Tattersall GJ (2), Abe AS (3)
}

(1) Laboratory of Herpetology, Butantan Institute, São Paulo, São Paulo State, Brazil; (2) Department of Biological Sciences, Brock University, St. Catharines, Ontario, Canada; (3) Department of Zoology, São Paulo State University (UNESP - Univ Estadual Paulista), Rio Claro, São Paulo State, Brazil.

\begin{abstract}
Snakes that can ingest prey that are proportionally large have high metabolic rates during digestion. This great increase in metabolic rate (specific dynamic action - SDA) may create a significant augment in the animal's body temperature. The present study investigated postprandial thermogenesis in Bothrops moojeni. Briefly, two groups of snakes were fed meals equivalent to $17 \pm 3 \%$ and $32 \pm 5 \%$ of their body weight and were observed for 72 hours, in which thermal images of each snake were taken with an infrared camera in a thermostable environment with a constant air temperature of $30^{\circ} \mathrm{C}$. The results showed a significant increase in snake surface temperature, with a thermal peak between 33 and 36 hours after feeding. The meal size had a great impact on the intensity and duration of the thermogenic response. Such increase in temperature appears to be connected with the huge increase in metabolic rates during digestion of relatively large prey by snakes that feed infrequently. The ecologic implication of the thermogenic response is still not well understood; however, it is possible that its presence could affect behaviors associated with the snake digestion, such as postprandial thermophily.
\end{abstract}

Key words: Bothrops, thermogenesis, feeding behavior, digestion.

\section{INTRODUCTION}

It is well known that the maintenance of body temperature among endotherms is associated with the high metabolic rate and the low thermal conductance of these animals; on the other hand, the high thermal conductance and the low metabolic rates associated with ectothermy hinder most of these animals from keeping an elevated temperature during metabolism (1). However, some ectotherms are able to keep their body temperature higher than air temperature through their metabolism, at least under some conditions (2). Among reptiles, the leatherback turtles are known for keeping their body temperatures higher than their surroundings, due to their metabolic rate, size, and insulation (3). Some brooding pythons keep the temperature of their eggs higher than the environment temperature, coiling around them and producing heat through muscle contractions (shivering thermogenesis) during the incubation period (4). Moreover, other reptiles through great increases in metabolic rate and behavioral adjustments are able to keep their body temperature higher than ambient temperature for some time (5).

The ingestion of proportionally large prey and infrequent feeding are common characteristics among ambusher snakes. To undertake this huge digestion process, these animals show several histological and physiological changes in their gastrointestinal tract, and such process is directly connected to a significant increase in their metabolic rate (6-11). The metabolic rate increase during the digestion process and food absorption is called the specific dynamic action (SDA), and 
although this is a common phenomenon in any digestion process, it is its dimension in snakes that draws our attention (12-16). Great increases in the snakes' aerobic metabolism are related to SDA, these increases are many times higher than those occurring from intense physical activities (15-19). Among the several factors that influence SDA, one of the most important is the relative prey size (14-16). Like in other metabolic activities, a great part of the energy produced is dissipated as heat, and therefore, high postprandial metabolic rates in these animals seem to be associated with a significant thermogenic process (5).

The aim of the present study was to evaluate the effect of different food sizes on postprandial thermogenesis in an ambush predator ectotherm, which can readily ingest prey of great proportion in nature (20).

\section{MATERIALS AND METHODS}

\section{Animals and Maintenance}

Eleven subadult specimens of Bothrops moojeni (six males and five females) were obtained from the Laboratory of Herpetology of Butantan Institute, whose mean mass was $132.1 \pm 16.2 \mathrm{~g}$.

\section{Experimental Protocol}

The animals were randomly divided into two groups and fed once during the experiment with pre-sacrificed mice (previously killed by cervical dislocation). Group A was fed $17 \pm 3 \%$ of body weight and Group B, $32 \pm 5 \%$ of body weight. These feeding proportions are close to the voluntary intake by the animals in the laboratory and close to that for many potential preys in the wild. Both groups were fasted for 30 days before the experiment. During the experiment, animals were kept in plastic cages $(40 \times 25 \times 20 \mathrm{~cm})$, which were put in two temperature-controlled chambers at $30 \pm 0.2^{\circ} \mathrm{C}$. The whole study was approved by the Ethics Committee of the Butantan Institute.

\section{Infrared Imaging}

After a 24-hour stabilization period, thermal images were taken of these animals, starting at time 0 (pre-feeding) up to 72 hours post-feeding. An infrared capture camera, MycroScan Thermal Imager ${ }^{\circ}$ (MyChron Infrared, USA), with a $0.1^{\circ} \mathrm{C}$ resolution power was used. All thermal readings were automatically corrected for non-black bodies, yielding a $0.95 \%$ emissivity index, which was previously estimated for living tissues (5).

\section{Data Analysis and Statistics}

The images were analyzed with MikroSpec ${ }^{\oplus}$ RT software (Mikron Infrared Inc., USA). The surface temperatures at time 0 were compared to the postprandial temperatures by Dunnett's test, and the temperatures recorded for the different feeding groups by the Bonferroni test. A significance level of 0.05 was used for all tests.

\section{RESULTS}

The results showed a thermogenic response in both feeding groups (Figure 1). Group A displayed significant thermogenesis $(\mathrm{p}<0.05)$ between 12 and 60 hours postprandial, and the peak occurred during the $33^{\text {rd }}$ hour, reaching an average of $0.98^{\circ} \mathrm{C}$, varying from 0.7 to $1.3^{\circ} \mathrm{C}$. Group B showed a significant thermogenic response $(\mathrm{p}<0.01)$ at 12 hours postprandial until the end of the experiment at 72 hours. The thermogenic peak occurred during the $36^{\text {th }}$ hour, reaching an average of $1.44^{\circ} \mathrm{C}$, which varied from 1.3 to $1.6^{\circ} \mathrm{C}$. Group B showed a significantly higher thermogenic response than Group A from 33 hours postprandial until the end of the experiment at 72 hours $(\mathrm{p}<0.05)$ (Figure 2). There was no difference in thermogenic response between the genders $(p=0.328)$

\section{DISCUSSION}

The SDA values reported in the literature and their relation to the quantity of ingested food support the data presented in this paper (14-16). A postprandial thermogenesis study in rattlesnakes, using almost the same methodology, showed similar data compared to the findings of the present paper, but the thermal peak in rattlesnakes occurred around 23 and 42 hours post-feeding for groups that ingested food quantities of 10 to $25 \%$ and 26 to $51 \%$ body weight, respectively (5). The thermogenic peaks are the results of the maximum times of specific dynamic action, which seems to be especially correlated to the increase in the secretion rate of stomach acid and hypertrophy of intestinal, hepatic and cardiac tissues, which occur during the gastrointestinal digestion process $(5,7,10,21)$. Therefore, even 


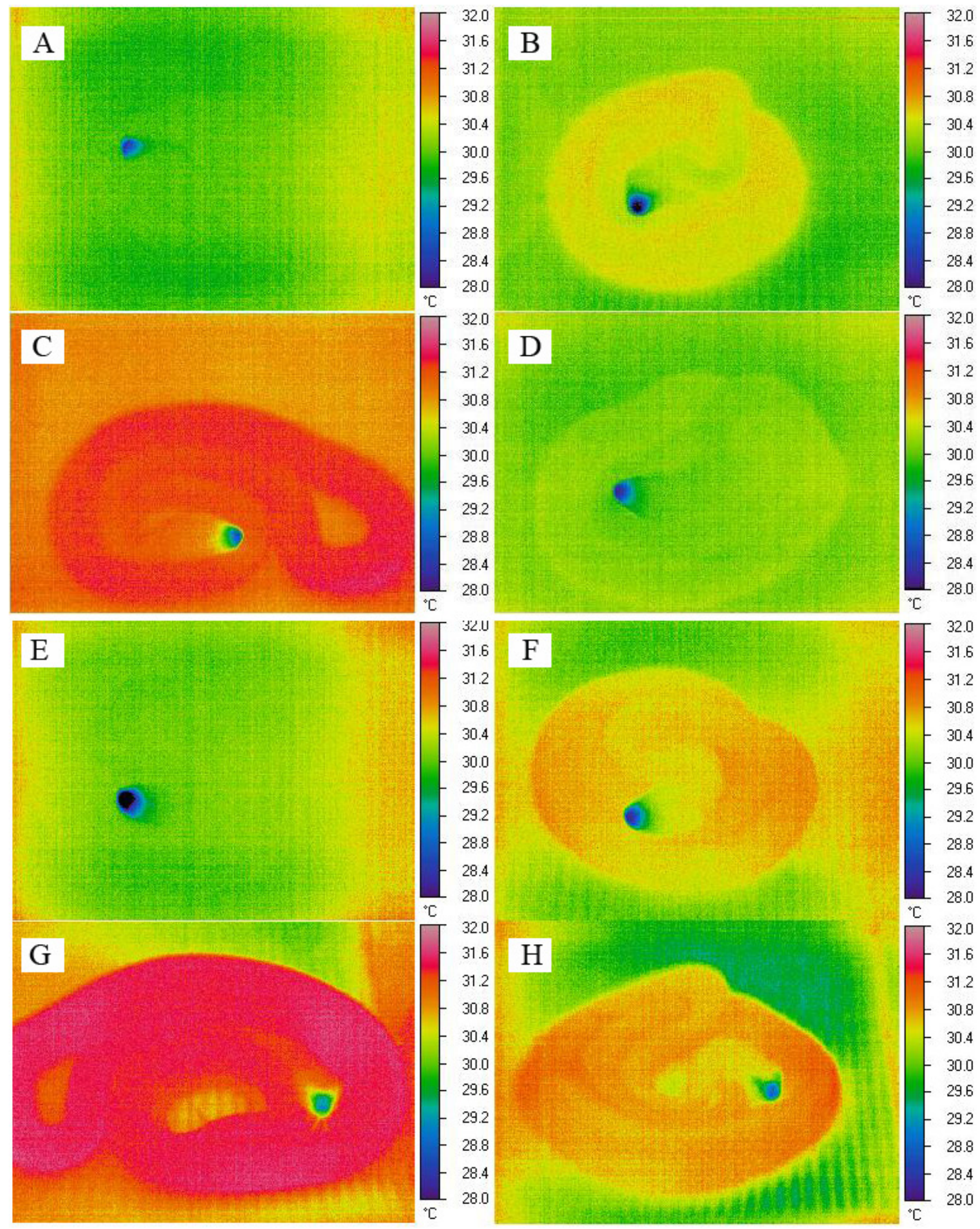

Figure 1. Thermal images of Group A (A-D) and Group B (E-H) 0, 24, 33 and 72 hours after feeding. Note that at 0 hour the temperature of the animal and the environment remains the same and no body shape can be seen (A, E). After 24 hours, the temperature of the animal is higher than the environment in both groups, and a body shape (snakes are coiled) is observed (B, F). After 33 hours the thermal peaks occur (C, G). After 72 hours there is almost no difference between the temperature of the Group $A$ and the chamber, but Group B still presented a higher temperature than the surroundings $(D, H)$. 


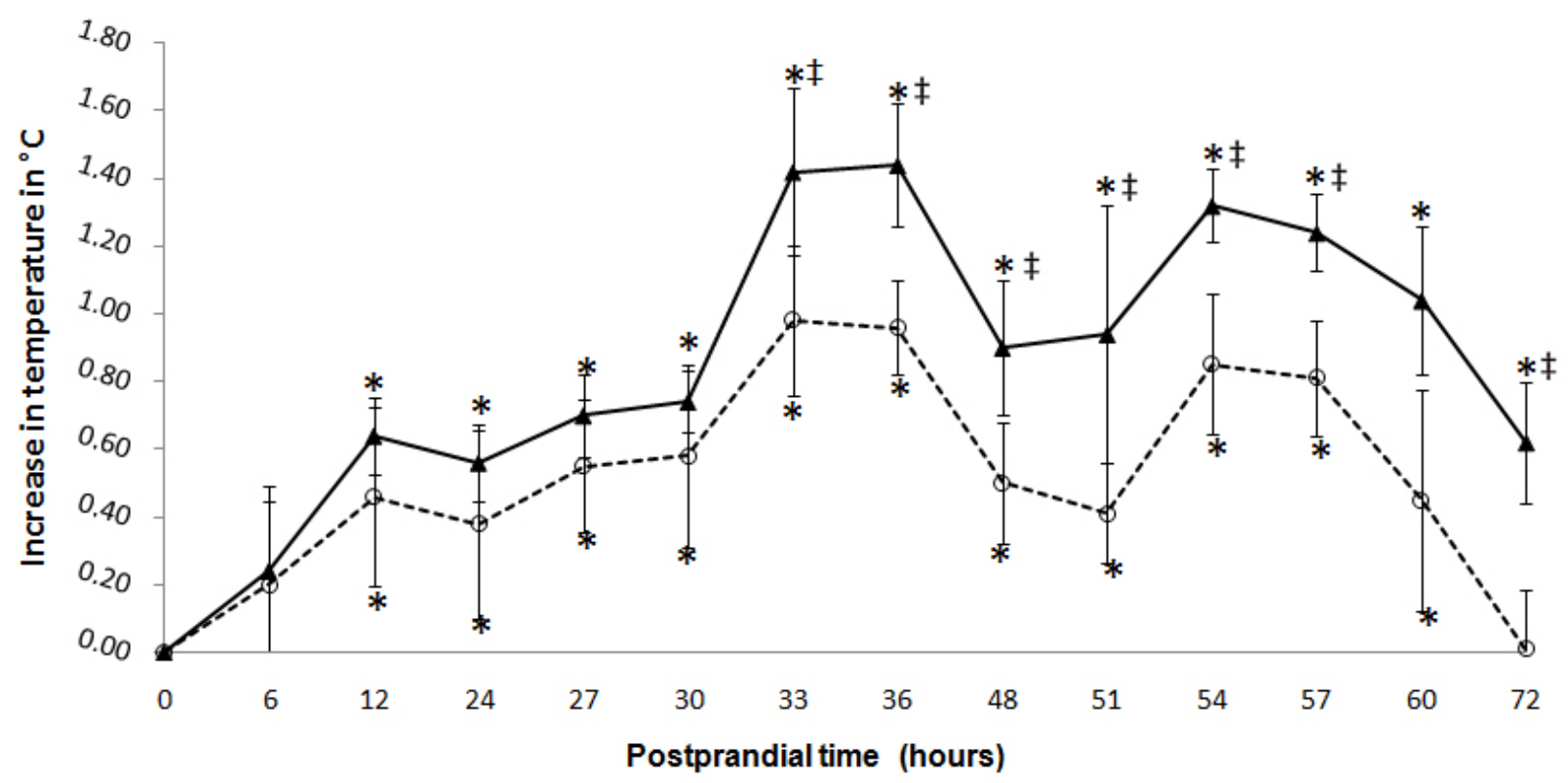

Figure 2. Increase in body temperatures as a function of time. The dashed line represents the Group A and the continuous line represents the animals in Group B. The bars represent the standard deviations. The symbol $(*)$ represents the statistically difference between the different hours and time zero. The symbol ( $\neq)$ represents the statistically differences between the groups $A$ and $B$ for the same time.

though the digestion process in these animals can last several days, the most significant portion of thermogenesis occurs during a smaller interval.

The thermal peaks in the previous and present studies are very similar. However, the rattlesnakes showed a SDA duration of about 2.5 times longer than for B. moojeni. This difference may be a reflex of the thermal conservation capacity related to the different size of the animals. Since the rattlesnakes used in the previous study have a smaller surface area compared to B. moojeni, they are able to keep their temperature above the external temperature for a longer time. The body size and the body surface area influence the animals' insulation capacity (22). Although the size of the snake has a smaller influence on the relative quantity of thermal energy created during SDA, it has an essential role during the heat conservation period, when we compare animals in the same posture (i.e., coiled).

Thermal photography is a noninvasive technique that makes it possible to evaluate an animal's surface temperature, but does not allow the determination of its internal body temperature (5). Hence, small increases in the body surfaces temperature during the thermogenic response are probably substantial underestimates of the true internal temperature increase, and increases in internal temperature on the order of $4^{\circ} \mathrm{C}$ have been reported in pythons through the use of data loggers (23).

Snakes in the wild are exposed to a relatively wide fluctuation in air temperature, and this factor has a huge impact on prey capture rates, time of digestion and energy consumption (15, 24-28). However, our experiment used a fixed temperature (within the normal thermal range sought by many snakes during the postprandial period) to better detect the physiologic heating process during the digestion without the bias of a cooling and heating process that normally occurs in the wild.

The physiologic importance of postprandial thermogenesis in these animals' life still has to be elucidated. It is possible that in animals that eat relatively larger prey there is a "buffering" of a possible postprandial thermophilic response, which is common in many snakes (24-28). Therefore, animals that ingest large proportions of food would have a relatively lesser need to search for higher environmental temperatures for more efficient digestion, since the metabolic heat production in these animals is considerably increased (5). A decrease in the need of a postprandial thermophilic response implies a lower transit rate in these animals during this 
period and consequently a lower predation risk to animals that probably have compromised defenses due to the great increase in mass (23). However, further studies are needed to assess the thermogenic and postprandial thermophilic responses in different animals for a better comprehension of how this postprandial increase in metabolic rate and the consequent heat produced affect their lives in nature.

\section{ACKNOWLEDGEMENTS}

Thanks are due to The State of São Paulo Research Foundation (FAPESP) for the financial support.

\section{COPYRIGHT}

(c) CEVAP 2011

\section{SUBMISSION STATUS}

Received: January 12, 2011.

Accepted: April 20, 2011.

Abstract published online: April 26, 2011.

Full paper published online: August 31, 2011.

\section{CONFLICTS OF INTEREST}

There is no conflict.

\section{FINANCIAL SOURCE}

The State of São Paulo Research Foundation (FAPESP), Brazil, provided the financial grants.

\section{ETHICS COMMITTEE APPROVAL}

The present study was approved by the Ethics Committee of the Butantan Institute (protocol number 334/06).

\section{CORRESPONDENCE TO}

DANIEL RODRIGUES STUGINSKI, Instituto Butantan, Rua Alvarenga, 1275, ap. 24A, São Paulo, SP, 05509-002, Brazil. Phone: +55 112507 5744. Email: dstuginski@yahoo.com.br.

\section{REFERENCES}

1. Bicego KC, Barros RC, Branco LG. Physiology of temperature regulation: comparative aspects. Comp Biochem Physiol. 2007;147(3):616-39.

2. Altringham JD, Block BA. Why do tuna maintain elevated slow muscle temperatures? Power output of muscle isolated from endothermic and ectothermic fish. J Exp Biol. 1997;200(Pt 20):2617-27.

3. Wallace BP, Jones TT. What makes marine turtles go: a review of metabolic rates and their consequences. J Exp Mar Biol Ecol. 2008;356(1-2):8-24.

4. Harlow P, Grigg G. Shivering thermogenesis in a brooding diamond python, Python spilotes spilotes. Copeia. 1984;1984(4):959-65.

5. Tattersall GJ, Milsom WK, Abe AS, Brito SP, Andrade DV. The thermogenesis of digestion in rattlesnakes. J Exp Biol. 2004;207(Pt 4):579-85.

6. Overgaard J, Wang T. Increase blood oxygen affinity during digestion in the snake Python molurus. J Exp Biol. 2002;205(Pt 1):3327-34.

7. Starck JM, Beese K. Structural flexibility of the small intestine and liver of garter snakes in response to feeding and fasting. J Exp Biol. 2002;205(Pt 10):137788.

8. Wang T, Zaar M, Arvedsen S, Vedel-Smith C, Overgaard J. Effects of temperature on the metabolic response to feeding in Python molurus. Comp Biochem Physiol A Mol Integr Physiol. 2002;133(3):519-27.

9. Lignot JH, Helmstetter C, Secor SM. Postprandial morphological response of the intestinal epithelium of the Burmese python (Python molurus). Comp Biochem Physiol A Mol Integr Physiol. 2005;141(3):280-91.

10. Secor SM. Evolutionary and cellular mechanisms regulating intestinal performance of amphibians and reptiles. Inter Comp Biol. 2005;45(2):282-94.

11. Ott BD, Secor SM. Adaptive regulation of digestive performance in the genus Python. J Exper Biol. 2006;210(1):340-56.

12. Garrow JS, Hawes SF. The role of amino acid oxidation in causing specific dynamic action' in man. Br J Nutr. 1972;27(1):211-9.

13. Machida Y. Study of specific dynamic action on some freshwater fishes. Rep USA Mar Biol Inst Kochi Univ. 1981;3(1):1-50.

14. Secor SM, Wooten JA, Cox CL. Effects of meal size, meal type, and body temperature on the specific dynamic action of anurans. J Comp Physiol B. 2007; 177(2):165-82.

15. Secor SM. Specific dynamic action: a review of the postprandial metabolic response. J Comp Physiol B. 2009;179(1):1-56.

16. Andrade DV, Cruz-Neto AP, Abe AS. Meal size and specific dynamic action in the rattlesnake Crotalus durissus durissus (Serpentes: Viperidae). Herpetologica. 1997;53(4):485-93.

17. Secor SM, Diamond J. Effects of meal size on postprandial responses in juvenile Burmese pythons (Python molurus). Am J Physiol. 1997;272(3 Pt 2):R902-12.

18. Secor SM, Boehm MC. Specific dynamic action of ambystomatid salamanders and the effects of meal size, meal type, and body temperature. Physiol Biochem Zool. 2006;79(4):720-35.

19. Toledo LF, Abe AS, Andrade DV. Temperature and meal size effects on the postprandial metabolism and energetics in a Boid snake. Physiol Biochem Zool. 2003;76(2):240-6.

20. Martins M, Marques OAV, Sazima I. Ecological and phylogenetic correlates of feeding habits in Neotropical pitvipers of the genus Bothrops. In: Schuett GW, Hoggren M, Douglas ME, Greene HW, editors. Biology of the vipers. Eagle Mountain, UT: Eagle Mountain Publishing; 2002. 307-28 p. 
21. Secor SM. Gastric function and its contribution to the postprandial metabolic response of the Burmese python Python molurus. J Exp Biol. 2003;206(Pt 10): 1621-30.

22. Schimidt-Nielsen K. Animal physiology: adaptation and environment. $5^{\text {th }}$ ed. New York: Cambridge University Press; 1997. 241-93 p.

23. Marcellini DL, Peters A. Preliminary observations on endogenous heat production after feeding in Python molurus. J Herpetol. 1982;16(1):92-5.

24. Greenwald OE, Kanter ME. The effects of temperature and behavioral thermorregulation on digestive efficiency in corn snakes (Elaphe guttata guttata. Physiol Zool. 1979;52(3):398-408.
25. Lysenko S, Gillis JE. The effect of ingestive status on the thermoregulatory behavior of Thamnophis sirtalis sirtalis and Thamnophis sirtalis parietalis. J Herpetol. 1980;14(2):155-9.

26. Naulleau G. The effects of temperature on digestion in Vipera aspis. J Herpetol. 1983;17(2):166-77.

27. Shine R, Slip DJ. Thermophilic response to feeding of the diamond python, Morelia s. spilota (Serpentes: Boidae) Comp Biochem Physiol A Physiol. 1988; 89(4):645-50.

28. Tsai TS, Tu MS. Postprandial thermophily in Chinese green tree vipers, Trimeresurus s. stejnegeri: interfering factors on snake temperature selection in a thigmothermal gradient. J Therm Biol. 2005;30(6):423-30. 